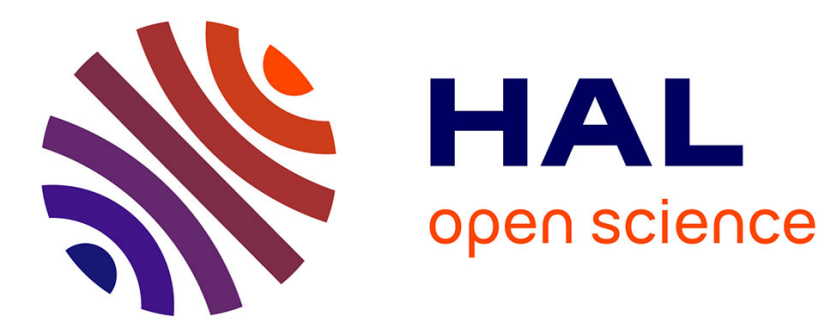

\title{
Synthesis and Use of Trifluoromethylthiolated Ketenimines
}

Frédéric R. Leroux, Thomas Guérin, Nadiia Pikun, Ryutaro Morioka, Armen

Panossian, Frédéric Leroux, Gilles Hanquet

\section{- To cite this version:}

Frédéric R. Leroux, Thomas Guérin, Nadiia Pikun, Ryutaro Morioka, Armen Panossian, et al.. Synthesis and Use of Trifluoromethylthiolated Ketenimines. Chemistry - A European Journal, 2020, 10.1002/chem.202002723 . hal-02990038

\section{HAL Id: hal-02990038 \\ https://hal.science/hal-02990038}

Submitted on 5 Nov 2020

HAL is a multi-disciplinary open access archive for the deposit and dissemination of scientific research documents, whether they are published or not. The documents may come from teaching and research institutions in France or abroad, or from public or private research centers.
L'archive ouverte pluridisciplinaire $\mathbf{H A L}$, est destinée au dépôt et à la diffusion de documents scientifiques de niveau recherche, publiés ou non, émanant des établissements d'enseignement et de recherche français ou étrangers, des laboratoires publics ou privés. 


\title{
Synthesis and use of trifluoromethylthiolated ketenimines
}

\author{
Thomas Guérin, ${ }^{[a]}$ Nadiia V. Pikun, ${ }^{[b]}$ Ryutaro Morioka, ${ }^{[c]}$ Armen Panossian, ${ }^{[a]}$ Gilles Hanquet ${ }^{*[a]}$ and \\ Frédéric R. Leroux ${ }^{\star[a]}$
}

\begin{abstract}
The synthesis of trifluoromethylthiolated ketenimines is herein described. They are easily synthesized from the corresponding a-trifluoromethylthiolated oximes upon activation with triflic anhydride and a base. The presumed nitrilium ion resulting from the Beckmann rearrangement is deprotonated to lead to the key intermediate, whose stability brought by the fluorinated substituent was unforeseeable. The reaction of these new building blocks with a variety of nucleophiles affords a vast array of cyclic and acyclic products bearing the valuable $\mathrm{SCF}_{3}$ moiety.
\end{abstract}

Decades of chemical research have shown that the fluorine atom and the fluorine-containing motifs profoundly impact the structure, reactivity and function of organic and inorganic molecules. ${ }^{[1]}$ Fluorine-containing compounds are nowadays synthesized in pharmaceuticals, agrochemicals, polymers and electronic research on a routine basis. As an example, it is well established that fluorine atom(s) and/or fluoroalkyl group(s) can lead to many beneficial effects in a biologically active molecule. ${ }^{[2,3]}$ In the past decade, fluorine chemistry greatly expanded with insightful contributions from research groups aiming at developing novel synthetic methods and reagents for the regio- and stereoselective introduction of fluorine or fluorine-containing groups into molecular scaffolds. Indeed, the fluorine chemistry field is still developing at a rapid pace and one of the current challenges is the search for Emergent Fluorinated Substituents (EFS) that would not only give new reactivity and functions to man-made molecules but also eventually lead to improved biological activity or even a novel mode of action. Such EFS are based on carbon (e.g. $\mathrm{CHF}_{2}$ ), on carbon linked to a heteroatom e.g. $\left(\mathrm{O}-\mathrm{CF}_{3}, \mathrm{~S}-\mathrm{CF}_{3}\right)$ or based on sulfur (e.g. $\mathrm{SF}_{5}$ ). From an industrial perspective, it should be noted that $\mathrm{CHF}_{2}, \mathrm{OCF}_{3}, \mathrm{SF}_{5}$ and $\mathrm{SCF}_{3}$ groups are quite rarely encountered and there is an urgent need to develop academic as well as industrial viable approaches towards scaffolds substituted by these EFS. ${ }^{[4]}$

The ways of introducing the EFSs are important as they are clearly cost-determining in a chosen synthetic route. In the early stage of drug development, the late-stage introduction of fluorinated moieties in advanced synthetic intermediates is highly desirable and various methods are now available; however, this late-stage introduction is tedious and relies on expensive

[a] Thomas Guérin, Dr. Armen Panossian, Dr. Gilles Hanquet, Dr. Frédéric Leroux

Université de Strasbourg, Université de Haute-Alsace, CNRS, UMR 7042-LIMA, ECPM, 25 Rue Becquerel, Strasbourg 67087, France E-mail: ghanquet@unistra.fr, frederic.leroux@unistra.fr

[b] Dr. Nadiia Pikun

Latvian Institute of Organic Synthesis, Aizkraukles Str. 21, Riga, LV1006, Latvia

[c] Ryutaro Morioka

Division of Chemistry, Faculty of Pure and Applied Sciences, University of Tsukuba, Tsukuba, Ibaraki, 305-8571, Japan

Supporting information for this article is given via a link at the end of the document

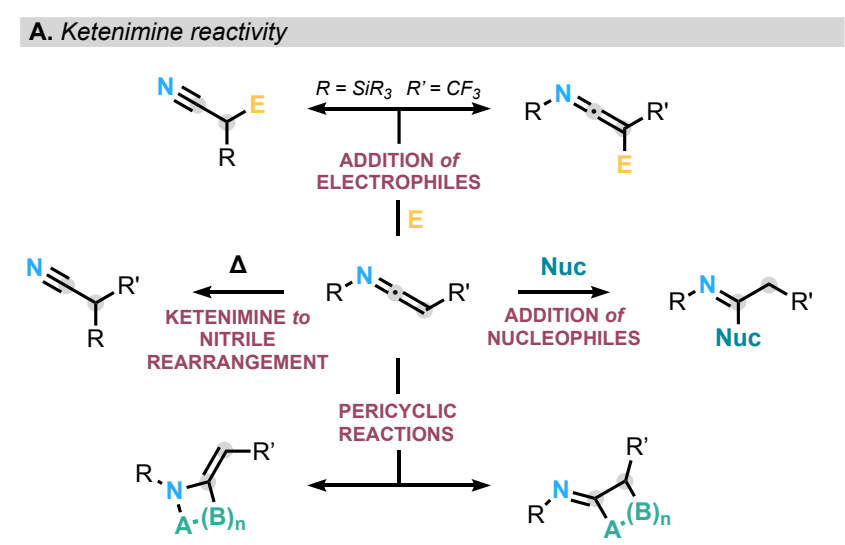

B. Known fluorinated ketenimines
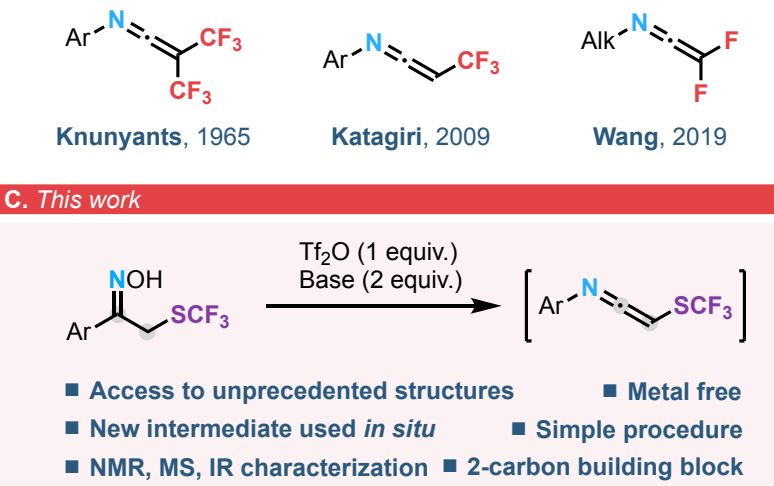

Scheme 1. Context of the present work.

reagents. ${ }^{[5]}$ On the other hand, most fluorinated compounds are often produced on an industrial scale from simple starting building blocks. ${ }^{[2 a-d]}$ Ketenimines are very versatile intermediates, capable of undergoing a variety of reactions such as nucleophilic additions and pericyclic reactions (Scheme 1, A) ${ }^{[6]}$ Among them fluorinated ketenimines are understudied, most likely as only few synthetic methods are available to prepare them. As a matter of fact since the seminal work of Knunyants in 1965 on bis(trifluoromethyl)arylketenimines, ${ }^{[7]}$ only the trifluoromethyl and bis(difluoro) derivatives by, respectively, Katagiri in $2009^{[8]}$ and Wang in 2019 ${ }^{[9]}$ were reported (Scheme 1, B). The $\mathrm{SCF}_{3}$ substituent has witnessed in recent years a huge interest and different methods for its direct introduction by means of electrophilic, nucleophilic as well as radical sources have been assessed. ${ }^{[10]}$ Therefore, we decided to try to access a ketenimine bearing the $\mathrm{SCF}_{3}$ moiety to further complete the range of fluorinated ketenimines available (Scheme 1, C). Access to ketenimine 1a was envisioned to be possible through the Beckmann rearrangement of ketoxime $\mathbf{2 a}$. Treatment of $\mathbf{2} \mathbf{a}$ with one equivalent of triflic anhydride in toluene, in the presence of two equivalents of Hünig's base led to a stable intermediate whose mass in GC-MS matched 1a's. The reaction was highly exothermic and, if carried out under air, the major product was 
amide 3 (Scheme 2) resulting from water addition onto the electrophilic $\mathrm{sp}$ carbon of 1a. All signs seemed to be strongly indicating of the effective formation of the desired ketenimine $\mathbf{1 a}$. Furthermore, the reaction of $\mathbf{1 a}$ with picric acid led to amide $\mathbf{4}$, presumably through Meisenheimer complex B produced after intramolecular cyclization of imidate $\mathbf{A}$ (Scheme 2). A solution of 1a under argon turned out to be stable for several days as indicated by GC-MS monitoring, yet any attempt to isolate it failed, leading to amide 3 .

Scheme 2. Synthesis of $1 \mathbf{a}$ and its reaction with oxygen-centered nucleophiles.
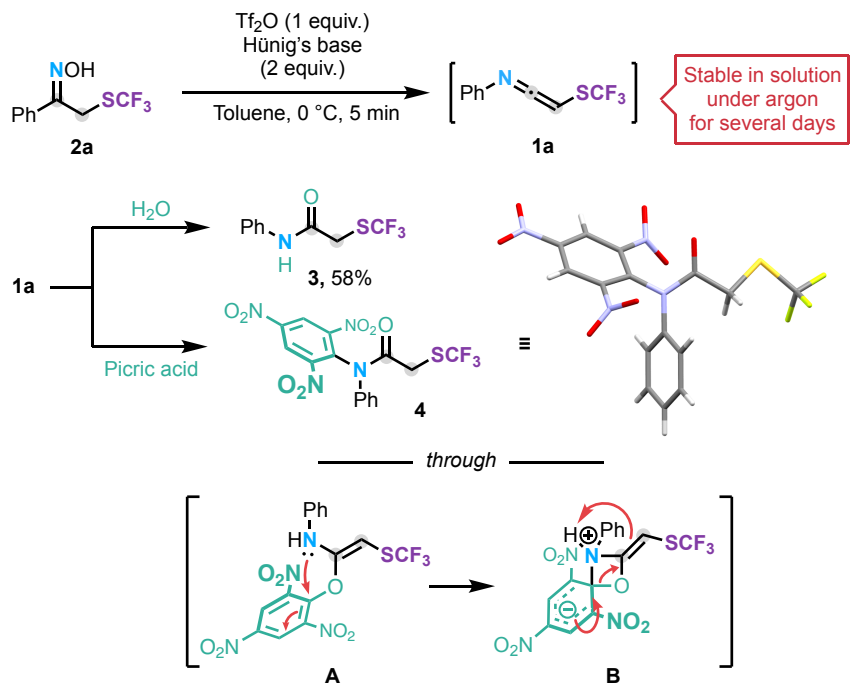

Though rather inclined to believe in the ketenimine nature of $\mathbf{1 a}$, we had to further characterize it. Although less coherent with the formation of $\mathbf{3}$ and $\mathbf{4}$, we could not totally exclude $\mathbf{1 a}$ to be actually azirine 5 produced by a Neber rearrangement, and isomassic to 1a. NMR leaned on the ketenimine side as the upfield proton was likely vinylic, despite its adjacent carbon being very shielded. Nevertheless, infrared analysis cleared all remaining doubt by showing a clear band at $2028 \mathrm{~cm}^{-1}$, characteristic of the stretching band $\mathrm{VN}=\mathrm{C}=\mathrm{C} .{ }^{[6 a]}$ Thus we are proposing the mechanism to be as follows (Scheme 3): first the oxime is converted into its triflic ether derivative I. I then undergoes a Beckmann rearrangement, the phenyl group migrates onto the nitrogen as the triflate anion departs, to form II, a mesomeric form of nitrilium III. II, or III is then deprotonated by the remaining equivalent of base to form ketenimine $\mathbf{1 a}$.

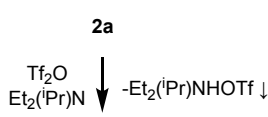

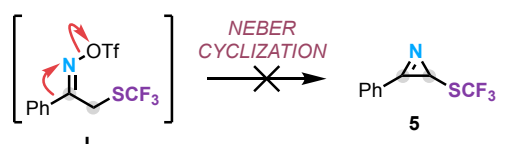

$$
\begin{aligned}
& \text { I BECKMANN }
\end{aligned}
$$

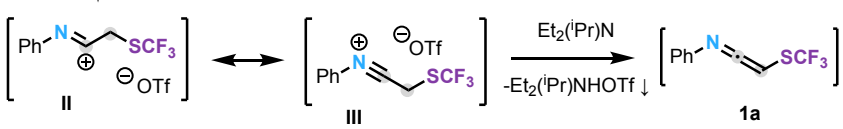

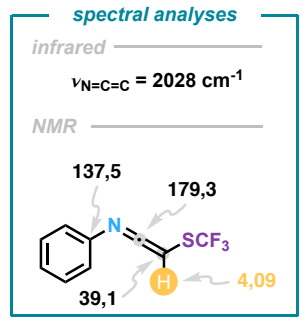

Scheme 3. Spectral data of $1 \mathrm{a}\left({ }^{13} \mathrm{C}\right.$ NMR shifts in blue and ${ }^{1} \mathrm{H}$ in yellow, in ppm, in $\left.\mathrm{C}_{6} \mathrm{D}_{6}\right)$ and a plausible mechanism for its formation.

Next, we submitted various amines to the reaction with intermediate 1a. We were delighted to observe a very clean GC chromatogram in each occurrence with only the expected product obtained in the reaction. After a rapid screening of bases and oxime activators (see supporting information) we studied the scope of the reaction (Scheme 4). Primary amines gave modest yields (products $6-8,10,11$ ), comparable to the one obtained with $\mathrm{N}, \mathrm{N}$-dimethylhydrazine (product 9 ). Secondary amines gave the corresponding amidines with better yields (12-15), that we attributed to their increased nucleophilicity. Modifying the aryl moiety for a $p$-anisyl group did not really affect the outcome of the reaction $(8,11)$ and we thus preferred to focus on the scope of nucleophiles. To our great pleasure thiols and phosphites react with $1 \mathrm{a}$ to give respectively thioimidate 16 and $\alpha$ aminophosphonate 17 (Scheme 4, A). In this last example, we believe the product forms via elimination of ethylene (Scheme 4, B). ${ }^{[11]}$ We were also pleased to see that malonitrile could add to 1a to form acrylonitrile 18. Several substrates, however, did not lead to the expected products. Indole left the ketenimine 1a unreacted while diethylphosphite led to a complex mixture. Unlike picric acid (see Scheme 2), aliphatic alcohols did not afford the corresponding imidates.

Scheme 4. Scope of the nucleophiles affording acyclic products. [a] 3 equiv. of

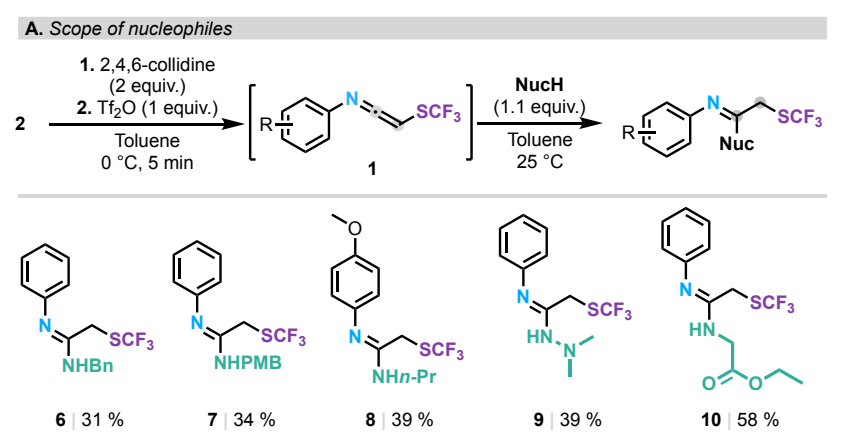<smiles>CCOC(=O)CNC(CS(C)(F)F)=Nc1ccc(OC)cc1</smiles><smiles>[134I]CC(=Nc1ccccc1)N1CCCC1</smiles>

$1264 \%$

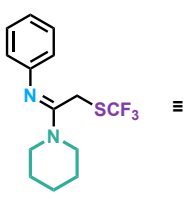

$13 \mid 52 \%$<smiles>[As]C/C(=N\c1ccccc1)N1CCOCC1</smiles>

$14 \mid 66 \%$
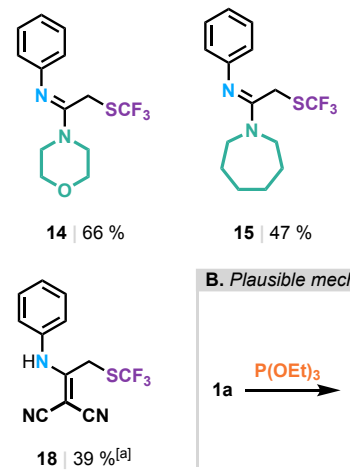

$15 \mid 47 \%$<smiles>CCOC(=O)CSC(CS(F)(F)F)=Nc1ccccc1</smiles>

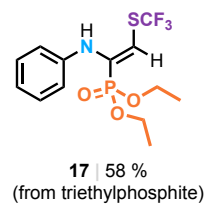

16 $50 \%$

B. Plausible mechanism for the formation of 17
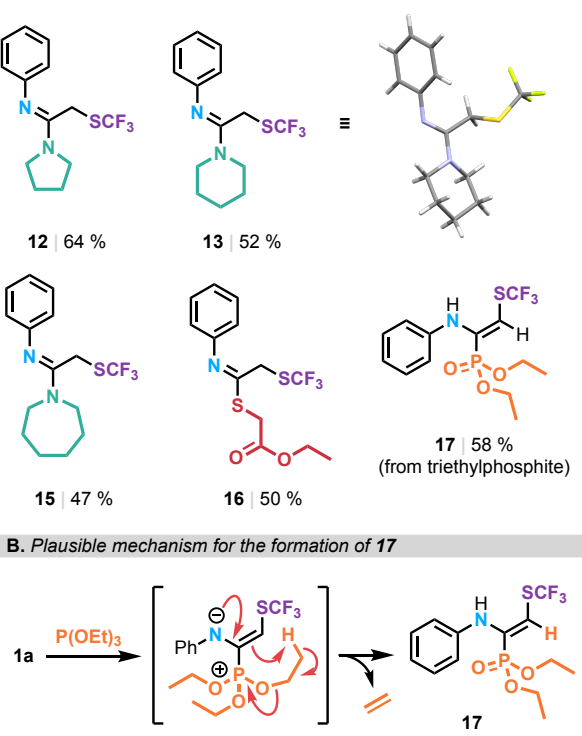

rom triethylphosphite)

base were used. 
We then envisioned using ambiphilic reagents, bearing both nucleophilic and electrophilic moieties in order to access the corresponding heterocyclic compounds after $\mathrm{N}$ - or $\mathrm{C}$ cyclization. ${ }^{[6]]}$ Our first attempts implied diverse salicylaldehydes derivatives. Although the reaction at room temperature was irreproducible, microwave conditions gave consistent results. Yet the isolated yield turned out to be quite poor, indeed product 19 was obtained in only $23 \%$ yield (Scheme 5). However, this methodology would provide the only alternative to access 3trifluoromethylthio coumarins (after hydrolysis) to the one described in the literature, using expensive AgSCF$_{3}{ }^{[12]} 1$ a could react similarly with benzoic or formic hydrazides to form the corresponding 1,2,4-triazoles $\mathbf{2 0}$ and $\mathbf{2 1}$ resulting from $\mathrm{N}$ cyclization.

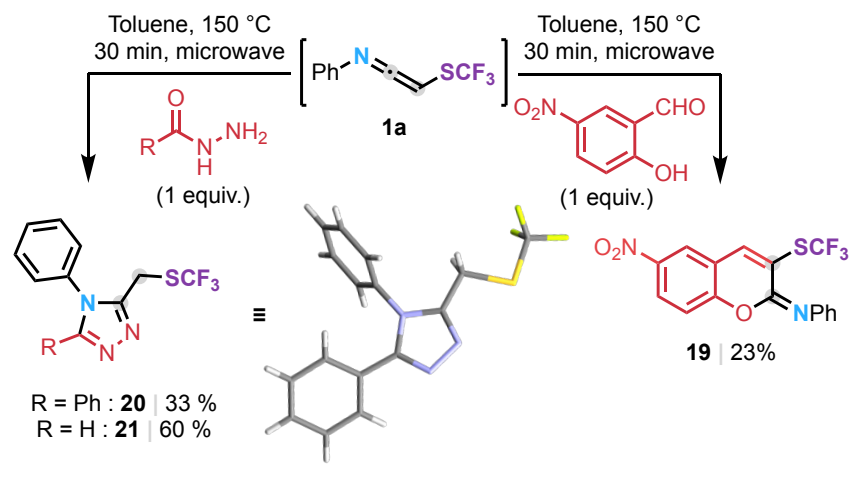

Scheme 5. Reaction with ambiphilic reagents.

Having established the feasibility to access heterocyclic compounds through $\mathrm{N}$ - or $\mathrm{C}$-cyclization, we wondered whether the aniline group resulting from the 1,2-phenyl shift could be eliminated by the condensation of a second nucleophilic position on the coupling partner. Thus, we used 2-hydrazinopyridine and could indeed isolate [1,2,4]triazolo[4,3-a]pyridine 22 in $68 \%$ yield (Scheme 6) from ketenimine $\mathbf{1 b}$.

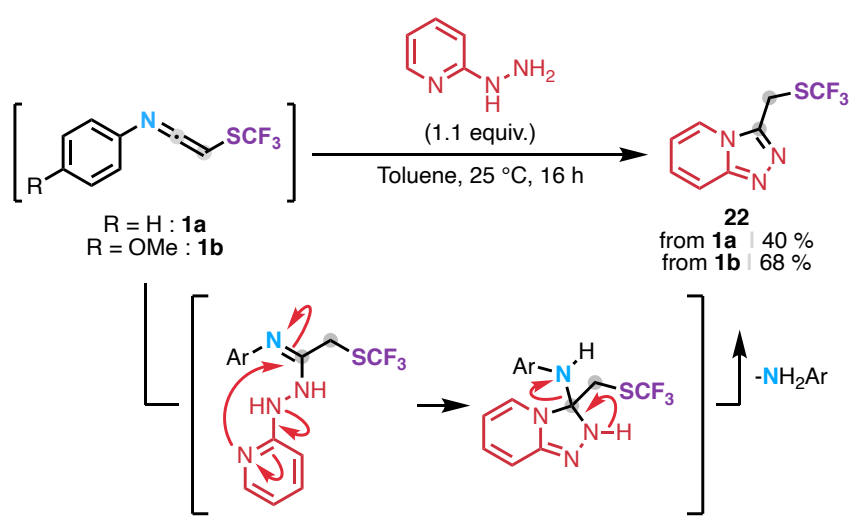

Scheme 6. Reaction with a bisnucleophilic reagent.

All of the aforementioned nucleophiles being well-defined electron-rich centers, we wondered if the reaction occurs with a masked nucleophile. For this we used trimethylsilyl azide in the hope to perform an azidotrimethylsilylation across one double bond of the ketenimine. Interestingly, the resulting product did not display the characteristic azide stretching band at ca. $2100 \mathrm{~cm}^{-1}$ in infrared spectroscopy. Our product bearing a $\mathrm{CH}_{2} \mathrm{SCF}_{3}$ moiety according to ${ }^{1} \mathrm{H}$ and ${ }^{13} \mathrm{C}$ NMR, we believe that the distal nitrogen of $\mathrm{TMSN}_{3}$ acts as any other nucleophile and attacks the sp carbon of 1 to form 23 and, after $N$-cyclization, intermediate 24 that rearomatizes through protodesilylation in the presence of water to give the corresponding $4 H$-tetrazoles 25 and 26 (Scheme 7).

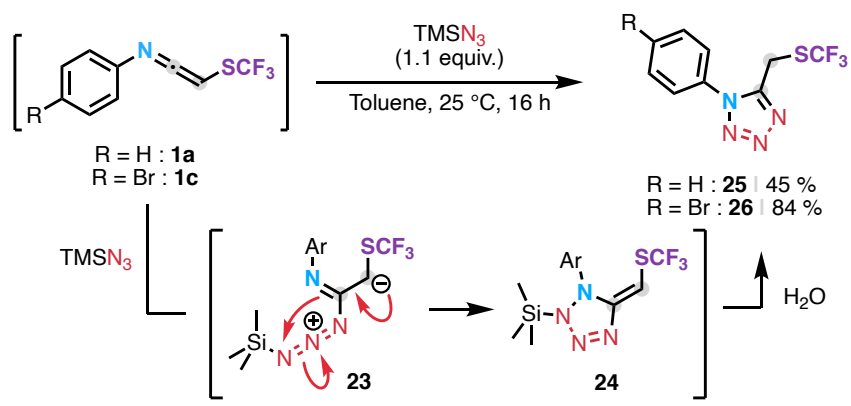

Scheme 7. Reaction with $\mathrm{TMSN}_{3}$ and cyclization of the presumed imidoyl azide intermediate.

In conclusion, we have developed a simple method to access trifluoromethylthiolated ketenimines. We could show that these unprecedented structures react under metal-free conditions with a variety of nucleophiles to form acyclic trifluoromethylthiolated products. When an electrophilic moiety is present on the nucleophilic reagent, trifluoromethylthiolated heterocycles can be synthesized, allowing for rapid structure diversification through the addition of a C-C-SCF 3 unit. The reactivity of the ketenimines in other types of reactions is currently being explored in our laboratory. These original intermediates should likely prove to be useful in the synthesis of bioactive compounds.

\section{Acknowledgements}

We gratefully acknowledge the French Agence Nationale pour la Recherche (ANR) (grant number ANR-17-CE07-0008-01, DEFIS), CNRS and Université de Strasbourg for financial support. T. G. is much grateful to the French Ministry of Education and Research for funding. N. P. was supported by the PostDoc project Nr.1.1.1.2/ VIAA/2/18/373. R. M. received a mobility grant from the University of Tsukuba. We thank L. Karmazin and C. Bailly from the Service de radiocristallographie de la Fédération de Chimie Le Bel FR 2010 for the SCXRD analyses. The French Fluorine Network (GIS Fluor) is also acknowledged.

Keywords: ketenimines - heterocycles - rearrangement organofluorine compounds $\bullet$ trifluoromethylthioethers

[1] a) P. Kirsch, Modern Fluoroorganic Chemistry, Wiley - VCH Verlag GmbH \& Co. KGaA, Weinheim, 2004; b) H. Groult, F. R. Leroux, A. Tressaud, Modern Synthesis Processes and Reactivity of Fluorinated Compounds, Elsevier Science, London, 2017; c) G. Haufe, F. R. Leroux, Fluorine in Life Sciences: Pharmaceuticals, Medicinal Diagnostics, and Agrochemicals, Academic Press, London, 2019. 
[2] For occurrence of fluorine in marketed drugs see:

a) H. Mei, J. Han, S. Fustero, M. Medio-Simon, D. M. Sedgwick, C. Santi, R. Ruzziconi, V. A. Soloshonok, Chem. Eur. J. 2019, 25, 11797; b) J. Wang, M. Sanchez-Rosello, J. L. Acena, C. del Pozo, A. E. Sorochinsky, S. Fustero, V. A. Soloshonok, H. Liu, Chem. Rev. 2014, 114, 2432; c) Y. Zhou, J. Wang, Z. Gu, S. Wang, W. Zhu, J. L. Acena, V. A. Soloshonok, K. Izawa, H. Liu, Chem. Rev. 2016, 116, 422; d) D. O'Hagan, J.Fluorine Chem. 2010, 131, 1071;

e) E. A. Ilardi, E. Vitaku, J. T. Njardarson, J. Med. Chem. 2014, 57, 2832.

[3] For reviews on the impact of fluorine in medicinal chemistry see: a) $\mathrm{K}$. Muller, C. Faeh, F. Diederich, Science 2007, 317, 1881; b) S. Purser, P. R. Moore, S. Swallow, V. Gouverneur, Chem. Soc. Rev. 2008, 37, 320; c) E. P. Gillis, K. J. Eastman, M. D. Hill, D. J. Donnelly, N. A. Meanwell, J. Med. Chem. 2015, 58, 8315; d) N. A. Meanwell, J. Med. Chem. 2018, 61, 5822.

[4] For reviews on some emergent fluorinated substituents see: a) F. Leroux P. Jeschke, M. Schlosser, Chem. Rev. 2005, 105, 827; b) P. Jeschke, E. Baston, F. Leroux, Mini-Reviews Med. Chem. 2007, 7, 1027; c) G. Landelle, A. Panossian, F. Leroux, Curr. Top. Med. Chem. 2014, 14, 941; d) F. Toulgoat, T. Billard, Chem. 2017, 2, 327; e) A. Tlili, F. Toulgoat, T. Billard, Angew. Chem. Int. Ed. 2016, 55, 11726; Angew. Chem. 2016, 128, 11900; f) T. Besset, P. Jubault, X. Pannecoucke, T. Poisson, Org. Chem. Front. 2016, 3, 1004; g) K. N. Lee, J. W. Lee, M. Y. Ngai, Tetrahedron 2018, 74, 7127; h) P. R. Savoie, J. T. Welch, Chem. Rev. 2015, 115, 1130; i) D. E. Yerien, S. Barata-Vallejo, A. Postigo, Chem. Eur. J. 2017, 23, 14676; j) X.-H. Xu, K. Matsuzaki, N. Shibata, Chem. Rev. 2015, 115, 731.

[5] a) S. Barata-Vallejo, S. Bonesi, A. Postigo, Org. Biomol. Chem. 2016, 14, 7150; b) K. N. Lee, J. W. Lee, M. Y. Ngai, Tetrahedron 2018, 74, 7127; c) X. Zhang, P. Tang, Sci. China Chem. 2019, 62, 525.

[6] For some reviews on ketenimine chemistry see: a) G. R. Krow, Angew. Chem. Int. Ed. 1971, 10, 435; Angew. Chem. 1971, 83, 455; b) N. P. Gambaryan, Usp. Khim. 1976, 45, 1251; c) P. Lu, Y. Wang, Synlett 2010, 165; d) S. E. Denmark, T. W. Wilson, Angew. Chem. Int. Ed. 2012, 51, 9980; Angew. Chem. 2012, 124, 10120; e) M. Alajarin, M. Marin-Luna, A. Vidal, Eur. J. Org. Chem. 2012, 2012, 5637; f) P. Lu, Y. Wang, Chem. Soc. Rev. 2012, 41, 5687; g) A. D. Allen, T. T. Tidwell, Chem. Rev. 2013, 113, 7287; h) R. H. Dodd, K. Cariou, Chem. Eur. J. 2018, 24, 2297.

[7] For the first synthesis of bis(trifluoromethyl)ketenimines see: a) N. P. Gambaryan, E. M. Rokhlin, Y. V. Zeifman, I. L. Knunyants, Izv. Akad. Nauk SSSR, Seriya Khimicheskaya 1965, 4, 749-750. For some applications see: b) D. P. Del'tsova, É. A. Avetisyan, N. P. Gambaryan, I. L. Knunyants, Izv. Akad. Nauk SSSR, Seriya Khimicheskaya 1973, 2, 355-358; c) Y. V. Zeifman, D. P. Del'tsova, É. A. Avetisyan, N. P. Gambaryan, I. L. Knunyants, Izv. Akad. Nauk SSSR, Seriya Khimicheskaya 1973, 8, 1785-1800; d) D. P. Del'tsova, N. P. Gambaryan, Izv. Akad. Nauk SSSR, Seriya Khimicheskaya 1973, 11, 25662572; e) N. P. Gambaryan, É. A. Avetisyan, Izv. Akad. Nauk SSSR, Seriya Khimicheskaya 1976, 2, 358-363; f) D. P. Del'tsova, N. P. Gambaryan, Izv. Akad. Nauk SSSR, Seriya Khimicheskaya 1976, 4, 858-862; g) Y. V. Zeifman, E. G. Ter-Garbiélyan, L. A. Simonyan, N. P. Gambaryan, I. L. Knunyants, Izv. Akad. Nauk SSSR, Seriya Khimicheskaya 1976, 8, 1813-1817; h) E. G. TerGarbiélyan, N. P. Gambaryan, Y. V. Zeifman, Izv. Akad. Nauk SSSR, Seriya Khimicheskaya 1978, 8, 1888-1891; i) L. A. Simonyan, Z. V. Safronova, N. P. Gambaryan, M. Y. Antipin, Y. T. Struchkov, Izv. Akad. Nauk SSSR, Seriya Khimicheskaya 1980, 2, 358-364; j) N. P. Gambaryan, D. P. Del'tsova, V. A. Livshits, E. G. Ter-Garbiélyan, Izv. Akad. Nauk SSSR, Seriya Khimicheskaya 1986, 10, 2344-2347.

[8] T. Katagiri, M. Handa, H. Asano, T. Asanuma, T. Mori, T. Jukurogi, K. Uneyama, J. Fluorine Chem. 2009, 130, 714.

[9] R. Zhang, Z. Zhang, Q. Zhou, L. Yu, J. Wang, Angew. Chem. Int. Ed. 2019, 58, 5744; Angew. Chem. 2019, 131, 5800.
[10] a) A. Tlili, T. Billard, Angew. Chem. Int. Ed. 2013, 52, 6818; Angew. Chem. 2013, 125, 6952; b) F. Toulgoat, S. Alazet, T. Billard, Eur. J. Org. Chem. 2014, 2014, 2415; c) H. Chachignon, D. Cahard, Chin. J. Chem. 2016, 34, 445; d) A.-L. Barthelemy, E. Magnier, G. Dagousset, Synthesis 2018, 50, 4765; e) Q. Glenadel, T. Billard, Eur. J. Org. Chem. 2016, 2016, 1955;

f) Q. Glenadel, M. Bordy, S. Alazet, A. Tlili, T. Billard, Asian J. Org. Chem. 2016, 5, 428; g) F. Toulgoat, T. Billard, in Modern Synthesis Processes and Reactivity of Fluorinated Compounds: Progress in Fluorine Science (Eds.: H. Groult, F. Leroux, A. Tressaud), Elsevier Science, London, 2017, pp. 141-179.

[11] S. S. Mykhaylychenko, N. V. Pikun, Y. G. Shermolovich, Tet. Lett. 2011, 52,4788 .

[12] M. H. Li, J. L. Petersen, J. M. Hoover, Org. Lett. 2017, 19, 638 
